\title{
Rumah Sakit Khusus Stroke dengan Penerapan Healing ENVIRONMENT DI SUKOHARJO
}

\author{
Karina Putri Pratiwi, MDE Purnomo, Mohamad Muqoffa \\ Program Studi Arsitektur \\ Fakultas Teknik \\ Universitas Sebelas Maret Surakarta \\ Email :karinaputripratiwi18@gmail.com
}

\begin{abstract}
Design of Special Hospital Stroke in Sukoharjo effected by the increase in cases of stroke from time to time, the main cause of death almost all hospitals are there in Indonesia, as well as yet of the existence of special handling psychologically for stroke patients particularly in Central Java, one area of Shorkot ever several times had the highest stroke cases. Design issues include: how to realize the design of container recovery process of health stroke patients by creating the quantity and quality of space or that can help cure using the application Healing Environment. The purpose of this design is as a container that hosts the health service in the territory of the People devoted to the sufferers of stroke that is designed using the method of healing by structuring the physical environment health facilities that can speed up the recovery time of the patient's health both physically and psychologically. The method used is the method of programming Architecture Palmer. The result is the design of hospitals that can accelerate the recovery process of health stroke patients both physically and psychologically with the application of the concept of the Healing Environment in outer space or space in hospitals, particularly in the treatment rooms.
\end{abstract}

Keywords: Healing Environment, Psychological, Special Hospital, Stroke.

\section{PENDAHULUAN}

Penyakit tidak menular adalah penyakit yang tidak dapat ditularkan kepada orang lain. Kondisi umum dan global penyebab kematian nomer satu Penyakit Tidak Menular (PTM) adalah penyakit kardiovaskuler.Menurut Jurnal Infodatin Jantung dari Kementrian Kesehatan RI,stroke merupakan salah satu penyakitkardiovaskuler dan tidak menular yang banyak terjadi dikalangan masyarakat lanjut usia karena tersumbat atau pecahnya pembuluh darah ke otak sehingga sel neuron di otak mengalami kematian yang menyebabkan seseorang mengalami kelumpuhan bahkan kematian, bahkandiperkirakan akan terus meningkat mencapai 23,3 juta kematian pada tahun 2030.

Menurut Kementrian Kesehatan Republik Indonesia, kasus-kasus penyakit stroke, khususnya di Jawa Tengah, pada tahun 2008-2012 mengalami penurunan. Hal ini menunjukkan pelayanan kesehatan untuk kasus penyakit stroke di Jawa Tengah semakin membaik. Hal ini juga terbukti dari adanya beberapa rumah sakit umum yang telah menyedikan unit khusus stroke dan syaraf, namun dilihat dari kasus stroke pada tahun 2013, Provinsi Jawa Tengah menduduki peringkat kedua dengan jumlah penderita stroke terbanyak dan peringkat ketiga dengan jumlah gejala stroke terbanyak. Peningkatan kesehatan yang semakin baik diharapkan dapat semakin menekan jumlah kasus penyakit stroke.

Menurut Astuti(2009), penanganan pasien penderita stroke yang diberikan pada rumah sakit umum rata-rata sama seperti penanganan untuk pasien lainnya sesuai aturan pelayanan medis di rumah sakit. Padahal penyakit stroke ini merupakan penyakit yang butuh penanganan khusus seperti yang disediakan pada Rumah Sakit Khusus Stroke, tetapi Provinsi Jawa Tengah belum mempunyai Rumah Sakit Khusus Stroke. Para pasien stroke biasanya di Jawa Tengah mendapatkan penanganan khusus pada rumah sakit yang telah memiliki unit stroke, sedangkan di Kota Sukoharjo ini hanya ada 3 rumah sakit yang mempunyai unit stroke yaitu, RSUD Sukoharjo, Rumah Sakit Prof. Dr. 
Soeharso, dan Yarsis. Hal ini tidak seimbang jika dilihat dari jumlah penderita stroke yang selalu meningkat setiap tahunnya sehingga para pasien stroke tidak tertampung semuanya pada unit stroke dan para penderita terpaksa dirawat di unit umum tanpa perawatan khusus yang mengakibatkan penyembuhan pasien akan terhambat dan berlangsung lebih lama.

Rumah sakit yang direncanakan untuk penderita stroke sebaiknya mempunyai desain yang dapat membantu pemulihan secara fisik maupun psikologis penderita sehingga proses pemulihan dapat berlangsung lebih cepat. Pada konsep Healing Environment mengolah tiga objek yang berbeda untuk membantu proses penyembuhan diri pada seseorang yang meliputi alam, indra, dan psikologis.Penerapan konsep Healing Environment pada rumah sakit khusus stroke sangat sesuai karena kesesuaian antara prinsip konsep ini dengan tujuan rumah sakit khusus stroke, yaitu dapat membantu mempercepat pemulihan para pasien stroke dari segi fisik maupun psikologis pasien.

\section{METODE}

Secara umum, untuk mencapai tujuan dan sasaran yang telah dirumuskan berdasar rumusan masalah dan persoalan, metode penyelesaian terdiri dari beberapa prosedur yang meliputi:

1. Gagasan dimulai dari keinginan Kementrian Kesehatan Republik Indonesia untuk menekan tingginya angka kematian yang disebabkan oleh penyakit stroke, mengetahui hanya ada satu Rumah Sakit Khusus Stroke di Indonesia yaitu RSNB (Rumah Sakit Stroke Nasional Bukittinggi). Kemudian didukung dengan pembangunan Yastroki (Yayasan Stroke Indonesia) yang berada dibeberapa daerah DKI Jakarta, sedangkan di wilayah Jawa Tengah dan daerah lainnya, belum ada penanganan khusus penyakit stroke dalam skala besar dan khusus.

2. Pemahaman awal dalam lingkup arsitektur tentang objek yang direncana, dimulai dari mendefinisi dan membuat pemahaman mengenai objek yang direncanakan, yaitu Rumah Sakit Khusus Stroke.

3. Penelusuran dan merumuskan masalah desain yang akan dijadikan sebagai acuan dalam perencanaan dan perancangan Rumah Sakit Khusus Stroke

4. Kajian pustaka yang dijadikan sebagai referensi baik dari sumber teoritik, preseden, maupun pengetahuan empirik yang terkait dengan penyakit stroke, rumah sakit dan rumah sakit stroke.

5. Analisis data dan informasi.

6. Analisis pendekatan gambaran umum dan spesifik objek yang akan dirancang dan perumusan konsep perencanaan (buliding concept atau concept of building).

7. Analisis pendekatan rumusan konsep perancangan (programming, design criteria and perfomancy of a design concept) yang lebih spesifik tentang objek yang akan dirancang.

8. Transformasi rancang bangun arsitektur dan rancangan awal (pra rancangan/ preliminery design).

\section{ANALISIS}

Pada perencanaan dan perancangan Rumah Sakit Khusus Stroke yangmenerapkan konsep Healing Environment pada tata ruang luar dan ruang dalamnyauntuk menciptakan suasana ruang yang menenangkan yang bertujuan untuk mempercepat proses pemulihan pasien stroke.

\subsection{Analisis Tapak}

Tujuan: Pemilihan tapak yang mendukung proses pemulihan pasien stroke.

1. Analisa Berdasarkan Pemintakatan.

3.1.1.1 Kriteria Penentu Pemintakatan.

1. Fungsi ruang pada bangunan.

2. Orientasi bangunan.

3. Sirkulasi didalam maupun di luar tapak.

4. Peraturan garis batas bangunan.

5. Kondisi topografi tapak.

\subsubsection{Penzoningan Kelompok Kegiatan}

1. Zona Publik

Zona yang berhubungan langsung dengan publik dan biasanya lokasi zona ini dekat dengan enterance, terutama main enterance.

2. Zona Semi Publik

Zona yang sifatnya umum tapi tidak langsung berhubungan dengan publik, namun letaknya berdekatan denganzona publik.

3. Zona Privat 
Zoan yang sifatnya pribadi atau khusus dan tidak memiliki hubungan dengan publik. Biasanya zona ini membutuhkan tingkat ketenangan dan kenyamanan paling tinggi di antara mintakat kelompok kegiatan yang lainnya.

4. Zona Servis

Zona yang merupakan zona penunjang zona lainnya, yaitu zona publik, zona semi publik, dan zona privat, namun zona ini juga memiliki zona khusus tersendiri yang letaknya terpisah dari zona-zona lain pada bangunan fasilitas umum.

\section{Analisa Sirkulasi Pencapaian}

Tujuan: Posisi peletakkan ME (Main Enterance), dan SE (Side Enternace) yang nyaman dan mudah diakses (lihat Gambar 1).

\subsubsection{Kriteria Penentu:}

1. Untuk main enterance (ME), dekat dengan jalan utama daerah sekitar.

2. Untuk side enterance (SE), diposisikan pada jalan yang lebih kecil (bukan jalan utama), namun apabila tidak ada, bisa dibuat alternatif untuk pembuatan jalan khusus untuk side enterance.

3. Pencapaian mudah dan aman

4. Pola sirkulasi di dalam tapak juga memperhatikan kondisi pola sirkulasi di sekitar tapak.

\subsubsection{Strategi Pencapaian}

Untuk pencapaian ke dalam tapak hanya bisa diakses melalui jalan utama di depan tapak. Jalur dua arah pada area tapak membuat tapak mudah untuk di akses dari arah barat maupun arah timur.

\subsubsection{Strategi Penentuan Pola Sirkulasi}

Strategi penentuan pola sirkulasi dalam tapak, meliputi:

1. Menentukan main enterance dan side enterance yang dapat diakses dengan mudah, aman dan nyaman baik menuju ke dalam tapak maupun ke luar tapak.

2. Pola sirkulasi di dalam tapak disesuaikan dengan tatanan massa dan pola kegiatan yang ada di dalam maupun di luar bangunan.

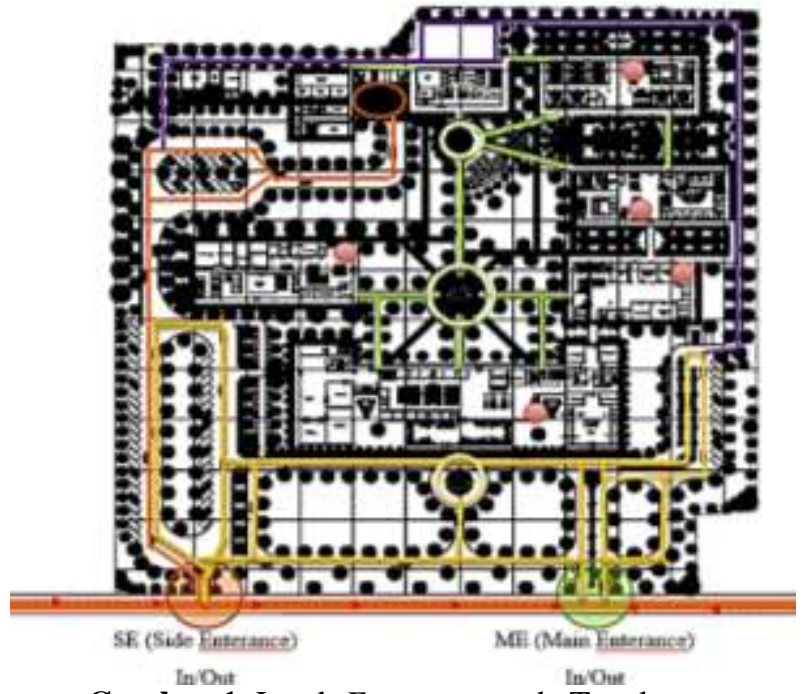

Gambar 1. Letak Enterance pada Tapak

\section{Analisa Berdasar Klimatologi}

Tujuan: Peletakan zona kelompok bangunan.

Kriteria Penentu:

1. Intensitas matahari.

2. Alur peredaran matahari terbit dan tenggelam.

3. Pemanfaatan potensi matahari, misalnya sebagai pencahayaan alami.

4. Kondisi cuaca dan iklim setempat

5. Penyesuain dengan Konsep Healing Environment.

Pada analisa klimatologi tersebut diterapkan untuk memperoleh arah massa bangunan dan penambahan vegetasi yang telah disesuaikan dengan klimatologi daerah setempat (lihat Gambar 2).

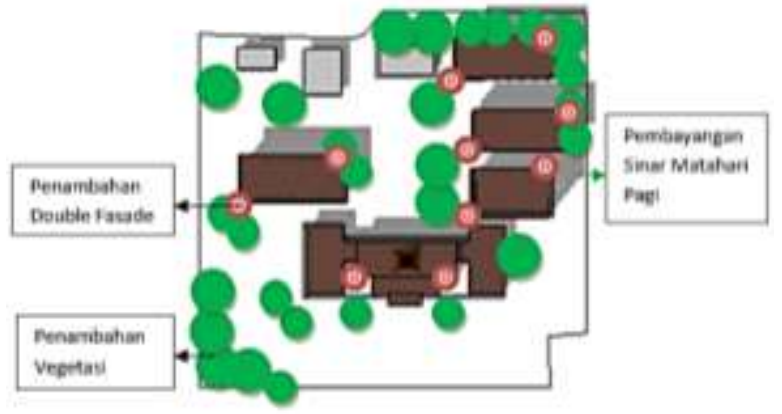

Gambar 2. Pola Tata Massa Bangunan dan Lansekap

\section{Analisa View dan Orientasi}

Tujuan: Peletakan zona kelompok bangunan.

1. Viewke dalam: view utama adalah pada jalan utama. Jalan ini sebagai jalur lalu lintas masyarakat di mana masyarakat melihat secara langsung ke arah bangunan. 
Dari view utama ini akan menghasilkan orientasi bangunan yang dapat dilihat secara utuh oleh masyarakat.

2. View ke luar: view utama dipilih pada area sekitar bangunan yang memiliki pemandangan yang menenangkan dan menyejukkan sesuai konsep Healing Environment.

Dari analisa tersebut didapatkan arah massa bangunan dari view positif dari luar bangunan dan view yang paling sesuai dari luar ke dalam bangunan(lihat Gambar 3).

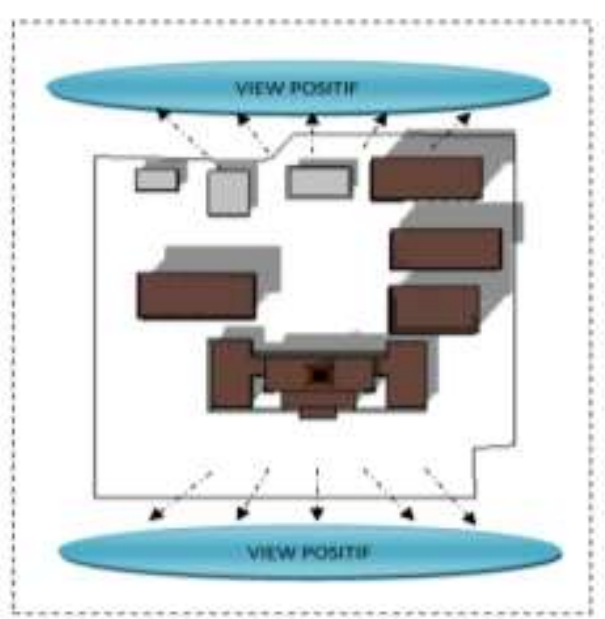

Gambar 3. Orientasi bangunan yang didapatkan dari view positif dari luar bangunan

\section{Analisa Kebisingan}

Tujuan: Peletakan zona kelompok bangunan.

1. Tingkat kebisingan area sekitar.

2. Sumber kebisingan area sekitar.

3. Posisi sumber kebisingan.

Pada analisa ini bertujuan memperoleh mintakat yang paling sesuai dengan tingkat kebisingan di lingkungan sekitar tapak (lihat Gambar 4).

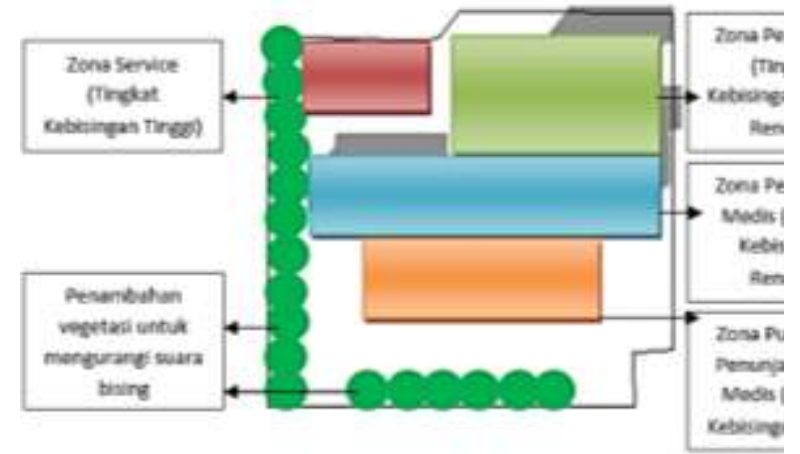

Gambar 4. Hasil Pemintakan dari Kebisingan Lingkungan Sekitar Tapak.

\subsection{Analisis Peruangan}

\subsubsection{Besaran Ruang}

Berikut ini adalah tabel yang menunjukkan total kebutuhan ruang yang dibutuhkan pada Rumah Sakit Khusus Stroke yang direncanakan (lihat Tabel 1).

Tabel 1. Besaran Ruang

\begin{tabular}{|l|c|}
\hline \multicolumn{1}{|c|}{ Ruang } & Luasan $\left.\mathbf{( m}^{\mathbf{2}}\right)$ \\
\hline Bangunan Administrasi & $745 \mathrm{~m}^{2}$ \\
\hline Bangunan Pengobatan & $914 \mathrm{~m}^{2}$ \\
\hline Bangunan Rehabilitasi & $1231 \mathrm{~m}^{2}$ \\
\hline Bangunan Perawatan & $2039 \mathrm{~m}^{2}$ \\
\hline Bangunan Penunjang Medis & $3560 \mathrm{~m}^{2}$ \\
\hline $\begin{array}{l}\text { Bangunan Penunjang Non- } \\
\text { Medis }\end{array}$ & $1507 \mathrm{~m}^{2}$ \\
\hline Bangunan Servis & $746 \mathrm{~m}^{2}$ \\
\hline Parking Area & $12.843 \mathrm{~m}^{2}$ \\
\hline Total Luasan & $23.585^{2}$ \\
\hline
\end{tabular}

\subsubsection{Hubungan Ruang}

Berikut ini adalah diagram yang menunjukkan hubungan-hubungan ruang berdasarkan respon pengguna terhadap organisasi ruang yang meliputi hubungan makro dan mikro.

\subsubsection{Hubungan Makro}

Pada analisis hubungan ruang ini menjelaskan hubungan langsung dan tak langsung antar ruang di dalam suatu tapak dan hubungan antar kelompok bangunan dengan zona pada tapak.

\subsubsection{Hubungan Mikro}

Pada analisis ini menjelaskan lebih detail hubungan ruang mikro antar kelompok kecil dengan ruang lainnya, sehingga antar kelompok ruang yang berdekatan mempunyai fungsi yang saling berkaitan erat, khususnya hubungan ruang untuk zona perawatan.

\subsubsection{Penataan Lansekap Bangunan Sekitar}

Menurut Jurnal Kurniawati (2011), lansekap bangunan sekitar diolah agar dapat menciptakan suasana lingkungan yang dapat mempercepat proses penyembuhan, yaitu dengan menggunakan konsep Healing Garden memanfaatkan vegetasi.

Penerapannya pada Rumah Sakit ini dapat dilihat komposisi warna bangunan dan tatanan lansekapnya (lihat Lampiran 1). 


\subsubsection{Pengolahan Ruang Dalam}

Menurut Jurnal Kurniawati (2011), ada 7 hal penting dalam pengolahan ruang dalam dengan penerapan Healing Environment yang meliputi:

1. Pencahayaan

2. Warna

3. View (Pemandangan)

4. Suara

5. Aroma

6. Seni

7. Tekstur

Penerapan 7 hal tersebut diharapkan dapat mempercepat pemulihan pasien stroke karena suasana ruang yang diciptakan merupakan elemen-elemen yang dapat mempengaruhi psikologis seseorang agar lebih tenang. Penerapan di dalam rumah sakit ini yang paling penting adalah pada bagian ruang rawat inap (lihat Lampiran 2).

\subsection{Analisa Utilitas}

Pada utilitas bangunan sebuah rumah sakit, harus mempunyai sistem pengolahan limbah agar saat pembuangan limbah tidak mencemari lingkungan sekitar. Pengolahan limbah di dalam rumah sakit ini terdiri dari 2 macam, yaitu pengolahan limbah cair (lihat Gambar 5) dan limbah padat (lihat Gambar 6).

\subsubsection{Pengolahan Limbah Cair}

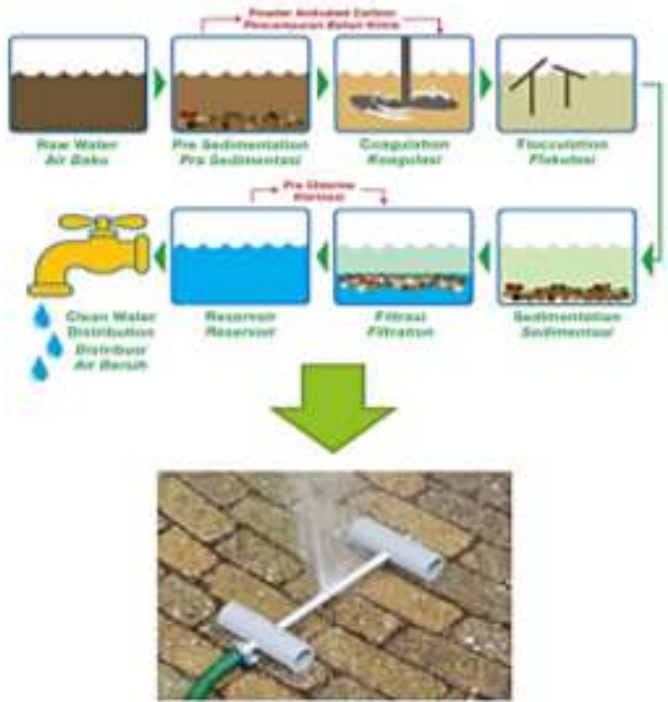

Gambar 5. Pemanfaatan Limbah Cair Menjadi Penyiram Tanaman

\subsubsection{Pengolahan Limbah Padat}

Skema Pengolahan Limbah Medis dengan Insinerator Maxpell

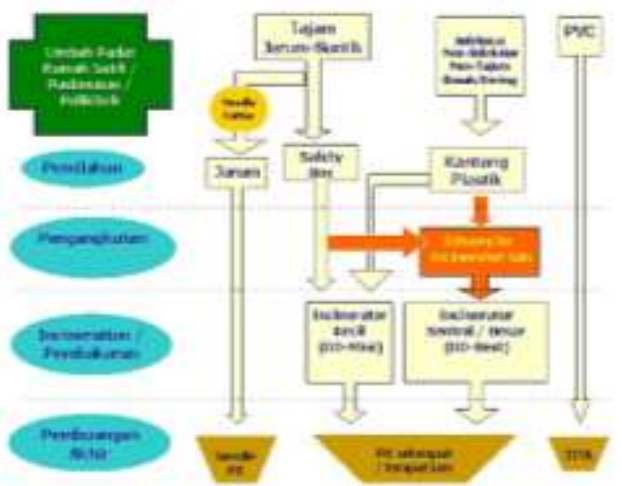

Gambar 6. Proses Pengolahan Limbah Padat dan Medis

\subsection{Analisis Bentuk dan Tampilan Bangunan}

Bentuk bangunan Rumah Sakit ini lebih ke bentuk dasar kotak karena ada beberapa peraturan dari PERMENKES yang mensyaratkan bangunan memiliki sirkulasi yang simpel, mudah di akses dan linier. Selain itu, bangunan sekitar memiliki bentuk bangunan yang modern dan cenderung ke kotak-kotak dengan perpaduan kaca-kaca pada tampilan bangunannya. Namun Solo Baru termasuk wilayah Sukoharjo yang juga masih melestarikan budaya setempat, sehingga untuk bangunan-bangunan resmi lingkungan sekitar mempunyai atap joglo, pelana dan sejenisnya.

Dari kedua budaya yang tersebut, sehingga bangunan Rumah Sakit ini akan dipadukan antara konsep bangunan modern dengan konsep budaya setempat yang menggunakan atap Joglo, serta persyaratan bangunan rumah sakit yang mengharuskan bangunannya bersih (lihat Gambar 7).

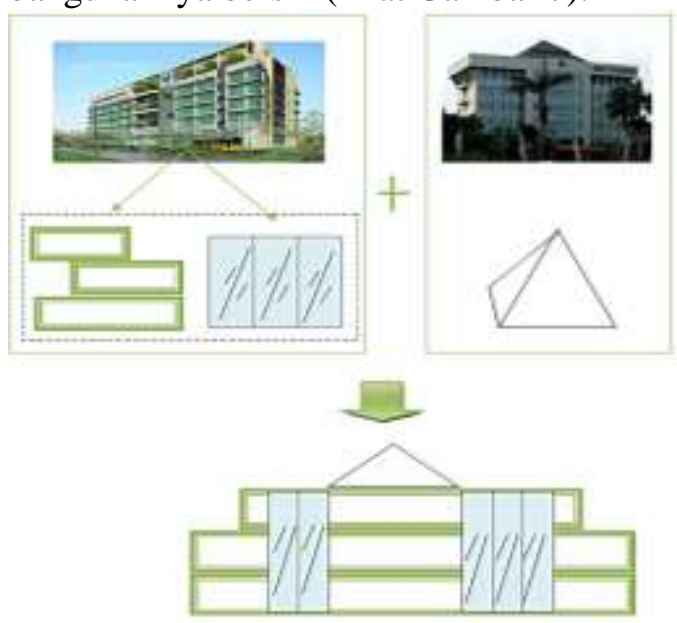


Gambar 7. Bentuk dan Tampilan yang Diadaptasikan dari Konteks Lingkungan Sekitar

\subsection{Analisis Struktur}

Bangunan Rumah Sakit Khusus Stroke ini mempunyai desain bangunan dengan jumlah lantai yang tidak terlau tinggi. Hal ini dikarenakan pasien yang tinggal disini merupakan pasien dengan kasus stroke yang rata-rata mengalami kelumpuhan pada organ tubuhnya. Konsep struktur yang diterapkan pada bangunan adalah efisiensi struktur dengan tujuan untuk memperkecil biaya pembangunan, yang meliputi

\subsubsection{Struktur Atap}

Atap yang digunakan pada desain Rumah Sakit ini adalah jenis atap limasan dengan rangka baja ringan (lihat Gambar 8)dan penutup atap dari genteng tanah liat.

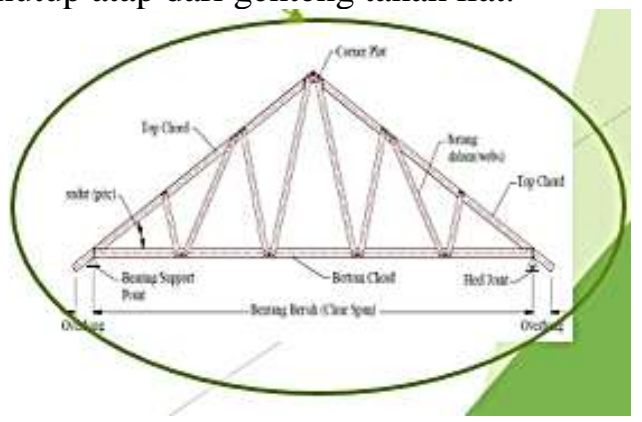

Gambar 8. Struktur Atap Bangunan

\subsubsection{Struktur Tengah Bangunan}

Kolom struktur menggunakan beton bertulang (lihat Gambar 9).

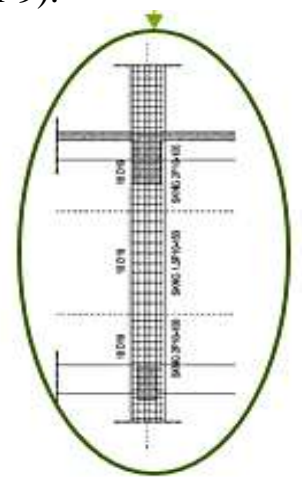

Gambar 9. Struktur Kolom Bangunan

\subsubsection{Struktur Bawah (Pondasi)}

Sistem pondasi menggunakan batu kali menerus dan pondasifootplat(lihat Gambar $10)$.

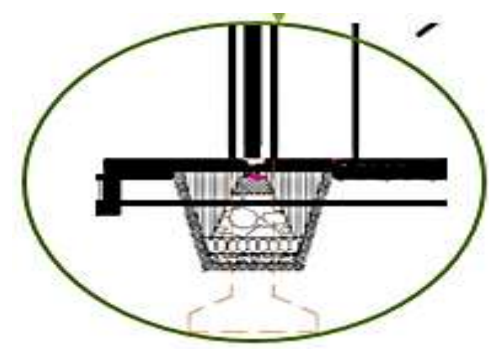

Gambar 10. Struktur Pondasi Bangunan

\section{KESIMPULAN (KONSEP DESAIN)}

Rumah Sakit Khusus Stroke menerapkanHealing Environmentpadaruang luar yaitu dengan pengolahan lansekap bangunan sekitar dengan menggunakan konsep Healing Garden (lihat Gambar 11 dan 12), sedangkan untuk ruang dalamnya, penerapan Healing Environmentditerapkan hampir pada seluruh ruang di dalam bangunan, namun yang paling utama diterapkan pada area front desk(lihat Gambar 13), poliklinik, dan ruang perawatan (lihat Gambar 14) yaitu:

1. Mengoptimakan pencahayaan didalam ruang bangunan.

2. Penggunaan warna-warna alam yang lembut dan natural.

3. Penggunaan natural sound untuk menciptakan suasana ruang yang menenangkan.

4. Penggunaan aromaterapi untuk pengharum ruangan.

5. Penambahan elemen tanaman untuk menciptakan suasana yang asri.

Rumah sakit ini mempunyai gambaran sebagai berikut:

Nama $\quad$ : Rumah Sakit Khusus Stroke.

Lokasi : Jl. Sukoharjo-Grogol.

Luas Lahan $\quad: \pm 48.000 \mathrm{~m}^{2}$.

Luas Bangunan : $23.585 \mathrm{~m}^{2}$.

Daya Tampung : 131 orang.

Kegiatan : Pencegahan, Perawatan, Pengobatan, khususnya untuk pasien stroke.

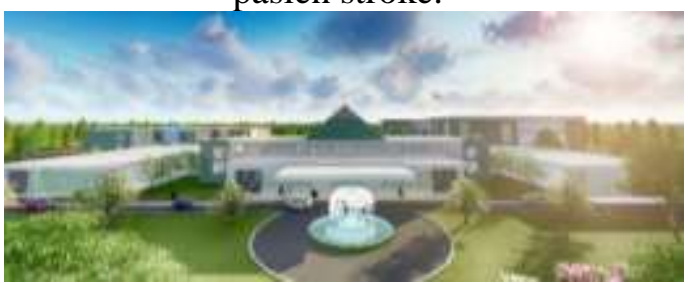

Gambar 11.Gambar Eksterior Bangunan Keseluruhan 


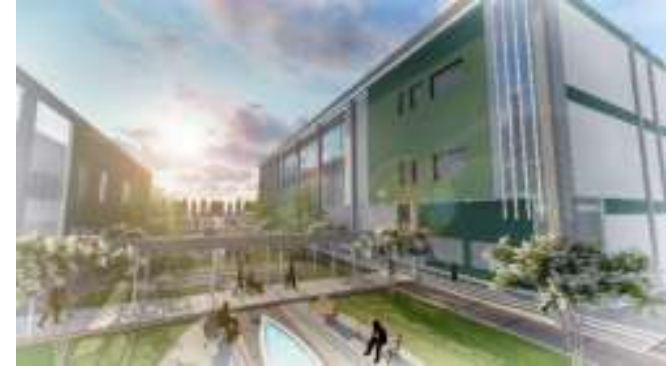

Gambar 12.Gambar Eksterior Pada Zona Perawatan

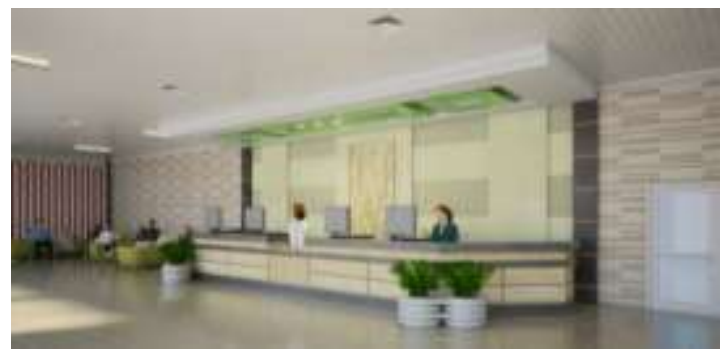

Gambar 13.Gambar Interior Front Desk

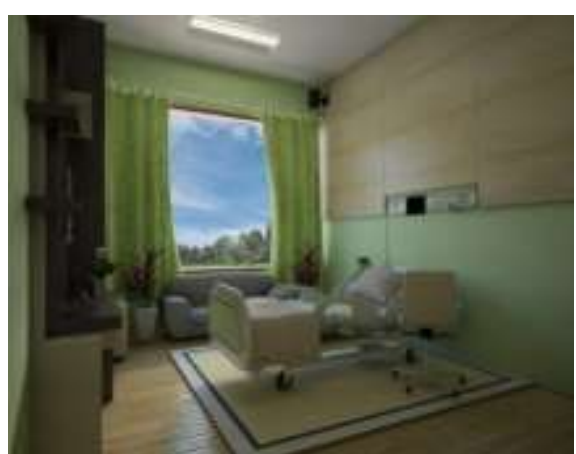

Gambar 14.Gambar Interior Ruang Rawat Inap

\section{REFERENSI}

Astuti, Endang Kusuma. 2009. Transaksi Terapeutik Dalam Upaya Pelayanan Medis di Rumah Sakit. Bandung: PT Citra Aditya Bakti.

Irdawati (2012). Pengaruh Latihan Gerak Terhadap Keseimbangan Pasien Stroke Non-Hemoragik. Dalam Jurnal Kesehatan Masyarakat [Online], vol 7 (2):

153-164.Tersedia: journal.unnes.ac.id > Home > Vol 7, No 2 (2012) > Irdawati [21 Desember 2015]

Kurniawati, Febriani (2011). Peran Healing Environment Terhadap Proses Penyembuhan. Jurnal Mahasiswa Jurusan Teknik Arsitektur 2007, FTUGM [Online]. Tersedia: 3https://www.scribd.com/doc/7625398 0/Peran-Healing-EnvironmentTerhadap-Proses-PenyembuhanTrauma-Psikis [21 Desember 2015] (2013). Situasi Kesehatan Jantung. Jurnal Infodatin Jantung: Pusdatin Kementrian Kesehatan RI [Online], 8 halaman. Tersedia: http://www.depkes.go.id/download.ph p?file $=$ download/pusdatin/infodatin/in fodatin-jantung.pdf [21 Desember 2015] 


\section{LAMPIRAN 1}

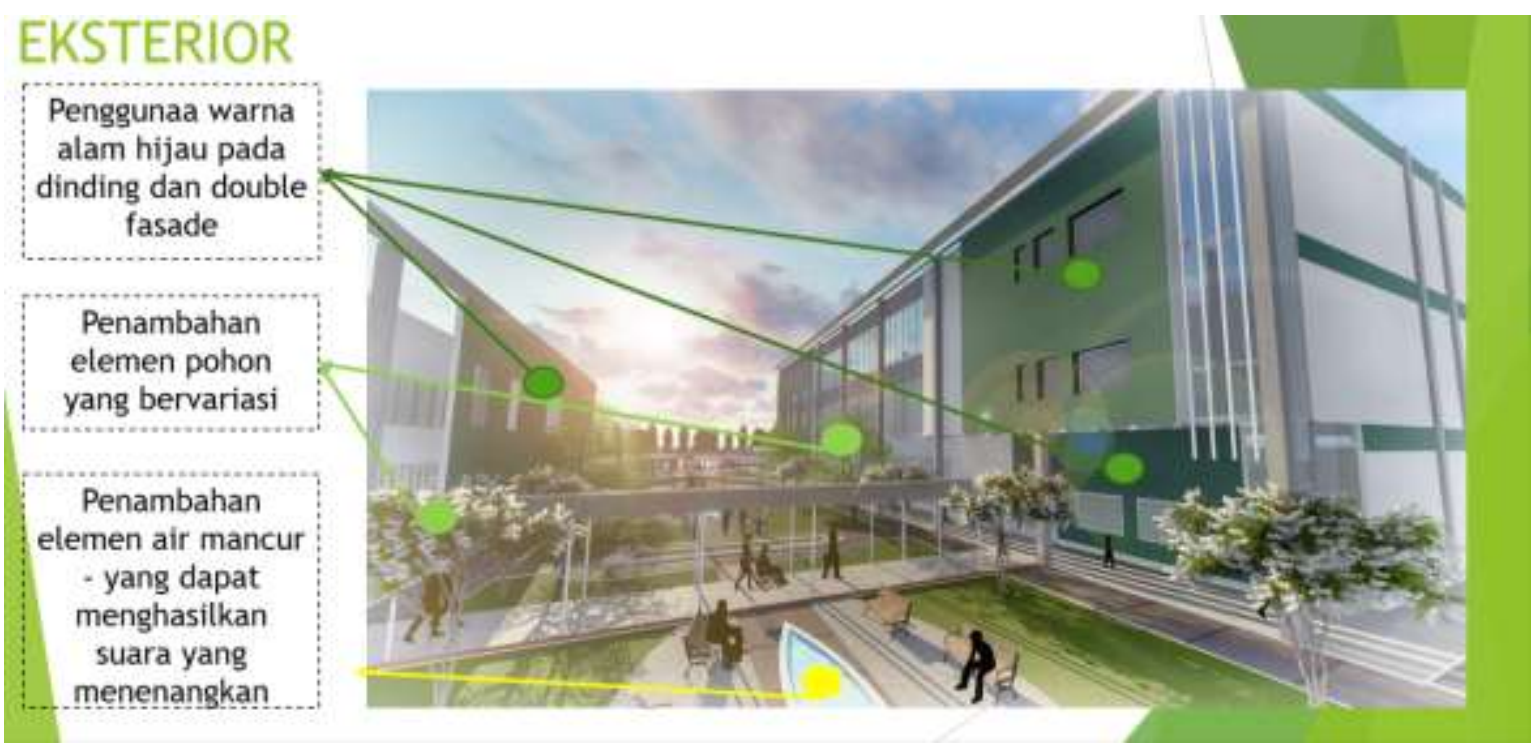

Gambar 15. Penekanan Healing Garden di Area Perawatan

\section{LAMPIRAN 2}

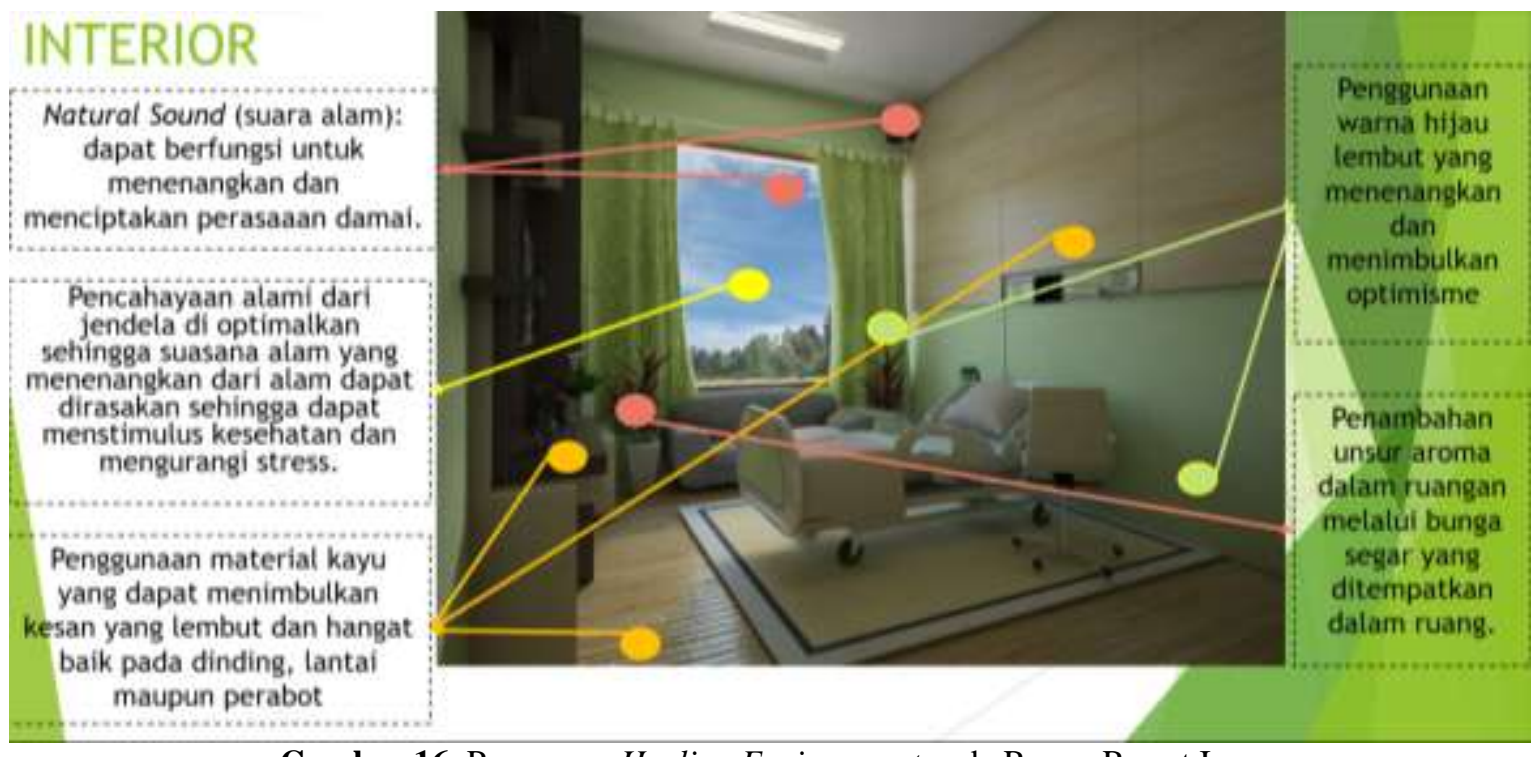

Gambar 16. Penerapan Healing Environment pada Ruang Rawat Inap 